\title{
Self-aligned mechanical attachment of carbon nanotubes to silicon dioxide structures by selective silicon dioxide chemical- vapor deposition
}

\author{
Jed D. Whittaker \\ jedwhit@hotmail.com \\ Ghaleb A. Husseini \\ ghaleb_husseini@hotmail.com \\ Matthew A. Linford \\ Robert C. Davis \\ Markus Brink \\ Follow this and additional works at: https://scholarsarchive.byu.edu/facpub \\ Part of the Biochemistry Commons, and the Chemistry Commons
}

\section{Original Publication Citation}

Whittaker, Jed D., Markus Brink, Ghaleb A. Husseini, Matthew R. Linford, and Robert C. Davis."Self-aligned mechanical attachment of carbon nanotubes to silicon dioxide structures by selective silicon dioxide chemical-vapor deposition." Applied Physics Le

\section{BYU ScholarsArchive Citation}

Whittaker, Jed D.; Husseini, Ghaleb A.; Linford, Matthew A.; Davis, Robert C.; and Brink, Markus, "Selfaligned mechanical attachment of carbon nanotubes to silicon dioxide structures by selective silicon dioxide chemical-vapor deposition" (2003). Faculty Publications. 464.

https://scholarsarchive.byu.edu/facpub/464

This Peer-Reviewed Article is brought to you for free and open access by BYU ScholarsArchive. It has been accepted for inclusion in Faculty Publications by an authorized administrator of BYU ScholarsArchive. For more information, please contact ellen_amatangelo@byu.edu. 


\title{
Self-aligned mechanical attachment of carbon nanotubes to silicon dioxide structures by selective silicon dioxide chemical-vapor deposition
}

\author{
Jed D. Whittaker \\ Department of Physics and Astronomy, Brigham Young University, Provo, Utah 84602 \\ Markus Brink \\ Laboratory of Atomic and Solid State Physics, Cornell University, Ithaca, New York 14853 \\ Ghaleb A. Husseini and Matthew R. Linford ${ }^{\text {a) }}$ \\ Department of Chemistry and Biochemistry, Brigham Young University, Provo, Utah 84602 \\ Robert C. Davis ${ }^{\text {b) }}$ \\ Department of Physics and Astronomy, Brigham Young University, Provo, Utah 84602
}

(Received 3 March 2003; accepted 30 October 2003)

\begin{abstract}
A self-aligned thin-film deposition technique was developed to mechanically attach carbon nanotubes to surfaces for the fabrication of structurally robust nanotube-based nanomechanical devices. Single-walled carbon nanotubes were grown by thermal chemical-vapor deposition (CVD) across 150 -nm-wide $\mathrm{SiO}_{2}$ trenches. The nanotubes were mechanically attached to the trench tops by selective silicon tetraacetate-based $\mathrm{SiO}_{2} \mathrm{CVD}$. No film was deposited on the nanotubes where they were suspended across the trenches. (C) 2003 American Institute of Physics.
\end{abstract}

[DOI: $10.1063 / 1.1636267]$

Single-walled carbon nanotubes (SWNTs) have been shown to possess extraordinary nanomechanical properties, ${ }^{1}$ such as a Young's modulus ${ }^{2}$ of $\sim 1 \mathrm{TPa}$ and a high aspect ratio. They have been used as cantilever beam flexural oscillators in the megahertz range ${ }^{2}$ and as atomic force microscope (AFM) probe tips ${ }^{3}$ for high-resolution imaging. Yet, these applications are currently limited by a mechanically weak Van der Waals attraction between the carbon nanotube (CNT) and the substrate. One method, ${ }^{4}$ developed to rigidly attach CNTs to AFM probe tips, uses an acrylic adhesive obtained from briefly sticking the probe tip to carbon tape before manually attaching the tube. Another $\operatorname{method}^{5}$ involves welding a CNT onto a silicon AFM probe tip using a scanning electron microscope (SEM) beam. While each method provides rigid attachment and significantly improves AFM resolution, they are both time consuming and yield CNT probes with inconsistent lengths and diameters.

We are pursuing self-aligned methods for nanomechanical fabrication. Self-alignment is currently a key technology in silicon device manufacturing, ${ }^{6}$ and could benefit nanomechanical fabrication processes because

(1) patterned layers can be produced without additional lithography steps and

(2) self-alignment can provide more accurate alignment than lithography.

Additionally, self-aligned methods are useful on threedimensional structures for which traditional lithography is difficult. For example, self-aligned processes have been useful for defining nanoscale features on AFM probe tips. ${ }^{7}$

We have developed a rigid attachment method to overcome the difficulties of individual CNT attachment, using the

\footnotetext{
${ }^{a)}$ Electronic mail: mrlinford@chemdept.byu.edu

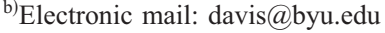

self-aligning thin-film deposition technique described here. A CNT was grown over a lithographically produced trench [Figs. 1(a) and 1(b)] and $\mathrm{SiO}_{2}$ was then deposited over the trench [Fig. 1(c)] to rigidly attach the CNT. The film was deposited selectively on the $\mathrm{SiO}_{2}$ surface, and did not cover the CNT where it was suspended over the trench. This resulted in a self-aligned attachment of the CNT where it contacted the $\mathrm{SiO}_{2}$ substrate. If this method had been nonselective, it would have also coated the CNT in the suspended region, increasing its diameter and altering its nanomechanical properties.

The trenches were produced by e-beam lithography in poly(methyl methacrylate) that was spun onto a $\mathrm{SiO}_{2}$ surface. Dry etching was used to transfer the pattern into the $\mathrm{SiO}_{2}$, resulting in trenches $150 \mathrm{~nm}$ wide and $40 \mathrm{~nm}$ deep.

The trenched wafer was dipped into a $150 \mu \mathrm{g} / \mathrm{ml}$ ferric nitrate nonahydrate in isopropyl alcohol catalyst solution. ${ }^{3}$ CNTs were then grown on the trench sample by chemicalvapor deposition (CVD) at $700{ }^{\circ} \mathrm{C}$. The CVD was done at atmospheric pressure with flow rates of $150 \mathrm{sccm}$ argon, 100 sccm hydrogen and $5.5 \mathrm{sccm}$ ethylene for $6 \mathrm{~min}$.

The $\mathrm{SiO}_{2}$ was thermally deposited from a silicon tetraacetate $\left[\mathrm{Si}\left(\mathrm{O}(\mathrm{O}) \mathrm{CCH}_{3}\right)_{4}\right]$ precursor in the reaction ${ }^{8}$ $\mathrm{Si}\left(\mathrm{O}(\mathrm{O}) \mathrm{CCH}_{3}\right)_{4}(\mathrm{~g}) \rightarrow \mathrm{SiO}_{2}(\mathrm{~s})+2\left(\mathrm{CH}_{3} \mathrm{CO}\right)_{2} \mathrm{O}(\mathrm{g})$, which occurs at $170{ }^{\circ} \mathrm{C}$. The $\left(\mathrm{CH}_{3} \mathrm{CO}\right)_{2} \mathrm{O}$, or acetic anhydride $(\mathrm{bp}$ (a)

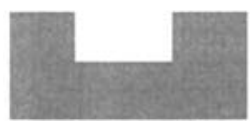

(b)

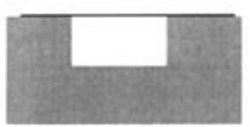

(c)

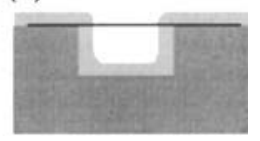

FIG. 1. Self-aligning thin-film attachment method overview. (a) A 40 $\times 150 \mathrm{~nm}$ trench is lithographically produced on a $\mathrm{SiO}_{2}$ substrate. (b) A CNT is grown over the trench by thermal CVD. (c) The substrate is selectively coated with $\mathrm{SiO}_{2}$ by a thermal CVD process that does not coat the suspended NT. 


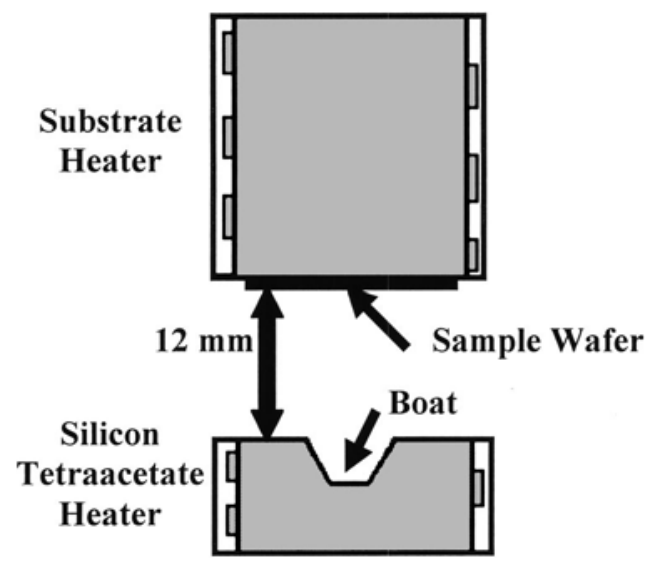

FIG. 2. Heating apparatus for silicon dioxide thermal CVD. The $\mathrm{Si}\left(\mathrm{O}(\mathrm{O}) \mathrm{CCH}_{3}\right)_{4}$ precursor is placed in the lower heater, where it is heated to $100^{\circ} \mathrm{C}$ and sublimes. The $\mathrm{SiO}_{2}$ substrate is placed on the upper heater, 12 $\mathrm{mm}$ above the $\mathrm{Si}\left(\mathrm{O}(\mathrm{O}) \mathrm{CCH}_{3}\right)_{4}$, and heated to $170{ }^{\circ} \mathrm{C}$ so that the reaction $\mathrm{Si}\left(\mathrm{O}(\mathrm{O}) \mathrm{CCH}_{3}\right)_{4}(\mathrm{~g}) \rightarrow \mathrm{SiO}_{2}(\mathrm{~s})+2\left(\mathrm{CH}_{3} \mathrm{CO}\right)_{2} \mathrm{O}(\mathrm{g})$ will occur. A shutter (not shown) separates the two stages. CVD is performed at 120 mTorr.

$\left.138-140^{\circ} \mathrm{C}\right)$, is volatile and is not incorporated into the film. The $\mathrm{Si}\left(\mathrm{O}(\mathrm{O}) \mathrm{CCH}_{3}\right)_{4}$ was heated to $100^{\circ} \mathrm{C}$, just below its $111-114^{\circ} \mathrm{C}$ melting point, while the CNT-trench sample was held at $170{ }^{\circ} \mathrm{C}$. The pressures at the $\mathrm{Si}\left(\mathrm{O}(\mathrm{O}) \mathrm{CCH}_{3}\right)_{4}$ source and the $\mathrm{SiO}_{2}$ sample surface were both 120 mTorr. A two-stage heating apparatus (Fig. 2) was specially designed for this CVD process. Each heater was connected to a variable voltage dc power supply and had a thermocouple to monitor temperature. The distance between the wafer substrate and the precursor sample was $12 \mathrm{~mm}$. A shutter separated the wafer substrate and precursor sample, and was removed during deposition. This allowed precise timing of film growth by blocking deposition until the heaters warmed to operating temperature. $\mathrm{SiO}_{2}$ film thickness was measured by variable-angle spectroscopic ellipsometry (M-2000, J.A. Woollam Co.). X-ray photoelectron spectroscopy (XPS) measurements were performed on an SSX-100 x-ray photoelectron spectrometer with an $\mathrm{Al} k_{\alpha}$ monochromatic source and a hemispherical analyzer.

$\mathrm{SiO}_{2}$ was deposited on the surface, patterned trench, and CNTs. The sample was examined by a Digital Instruments Dimension 3100 AFM and a Philips XL 30S FEG SEM. NT diameter was determined by measuring height in AFM crosssectional analysis. Cross-sectional analysis was also used to measure the height difference between the top of the CNT and the top of the grown film. Height measurements are pre-

TABLE I. Deposition rate trials for times from 10-40 min. All trials were performed on planar Si substrates, and the $\mathrm{Si}\left(\mathrm{O}(\mathrm{O}) \mathrm{CCH}_{3}\right)_{4}$ precursor was heated to between 97 and $104{ }^{\circ} \mathrm{C}$ for all cases. Oxide thicknesses before and after deposition were measured using ellipsometry.

\begin{tabular}{cccc}
\hline \hline $\begin{array}{c}\text { Silicon sample } \\
\text { temperature }\left({ }^{\circ} \mathrm{C}\right)\end{array}$ & $\begin{array}{c}\text { Time } \\
(\mathrm{min})\end{array}$ & $\begin{array}{c}\text { Deposited } \\
\text { thickness }(\mathrm{nm})\end{array}$ & $\begin{array}{c}\text { Rate } \\
(\mathrm{nm} / \mathrm{min})\end{array}$ \\
\hline 174 & 10 & 2.4 & 0.24 \\
171 & 10 & 2.5 & 0.25 \\
171 & 15 & 3.6 & 0.24 \\
172 & 30 & 4.4 & 0.15 \\
170 & 40 & 8.2 & 0.21 \\
& & Avg. rate: & 0.22 \\
\hline \hline
\end{tabular}
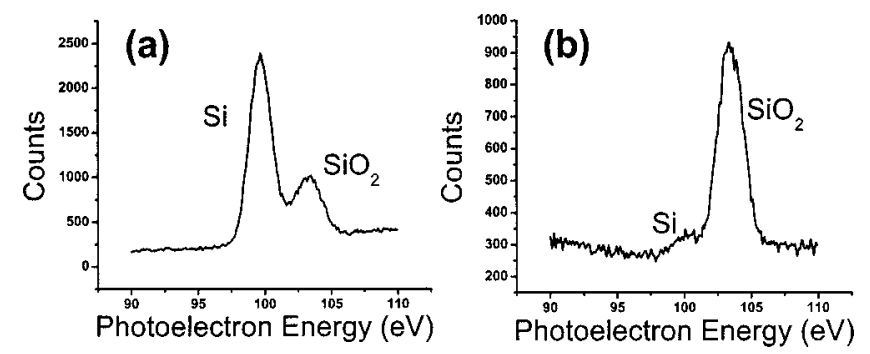

FIG. 3. XPS data of (a) native oxide and (b) deposited oxide. The Si wafer before deposition had spectral peaks characteristic of a native $\mathrm{SiO}_{2}$ film. After deposition, the wafer showed a significant increase in the strength of the $\mathrm{SiO}_{2}$ peak, relative to the $\mathrm{Si}-\mathrm{Si}$ peak. This shows that the deposited layer was $\mathrm{SiO}_{2}$.

sented without correction for chemical differences between CNTs and $\mathrm{SiO}_{2}$.

To confirm that $\mathrm{SiO}_{2}$ films were grown with our CVD apparatus, the $\mathrm{SiO}_{2}$ was first deposited on planar $\mathrm{Si}$ substrates and analyzed. The deposition rate was determined by ellipsometry to be $0.2 \mathrm{~nm} / \mathrm{min}$ (Table I). Composition and chemical bonding of the deposited film were studied by XPS. Figure 3 shows Si $2 p$ XPS narrow scans before and after $\mathrm{CVD}$ of $\mathrm{SiO}_{2}$. The lower binding energy component of these spectra comes from the bulk $\mathrm{Si}$ and the higher energy component comes from the $\mathrm{Si}$ in $\mathrm{SiO}_{2}$. The chemical shift of $\sim 4$ $\mathrm{eV}$ from the bulk $\mathrm{Si} 2 p$ XPS peak is consistent with $\mathrm{Si}$ bonded to four oxygen atoms, for example, $\mathrm{SiO}_{2} .{ }^{9}$ Prior to $\mathrm{SiO}_{2} \mathrm{CVD}$, the ratio of $\mathrm{Si}$ in $\mathrm{SiO}_{2}$ to $\mathrm{Si}$ in bulk silicon was 0.31 . After CVD, this ratio increased significantly to 16 . The increase of the $\mathrm{SiO}_{2}$ peak in relation to the $\mathrm{Si}$ peak verified that the deposited layer was $\mathrm{SiO}_{2}$. The XPS data was also used to calculate the $\mathrm{SiO}_{2}$ film thickness to confirm the ellipsometry data. ${ }^{10}$

Characterization of deposited films was followed by deposition on suspended CNT samples illustrated in Fig. 1. One of the several CNTs that spanned multiple trenches was found on the trench-nanotube sample by AFM, and landmarks were recorded so that the tube could be located again after processing. The CNT was measured by AFM to be 1.9 $\mathrm{nm}$ in diameter (a single-walled CNT), and rested on top of the trenches (Fig. 4). $\mathrm{SiO}_{2}$ was deposited by CVD on top of

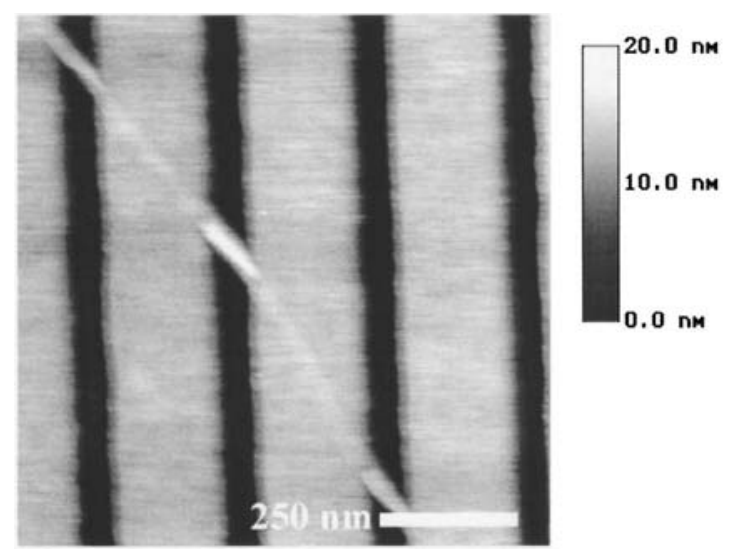

FIG. 4. AFM image of SWNT grown by CVD over trenches in $\mathrm{SiO}_{2}$. One of the many CNTs found resting on top of the trenches. Landmarks near the NT were recorded so that this specific tube could be located again and studied after $\mathrm{SiO}_{2}$ deposition. Cross-sectional analysis showed that the NT was $1.9 \mathrm{~nm}$ in diameter. Scale bar is $250 \mathrm{~nm}$. 


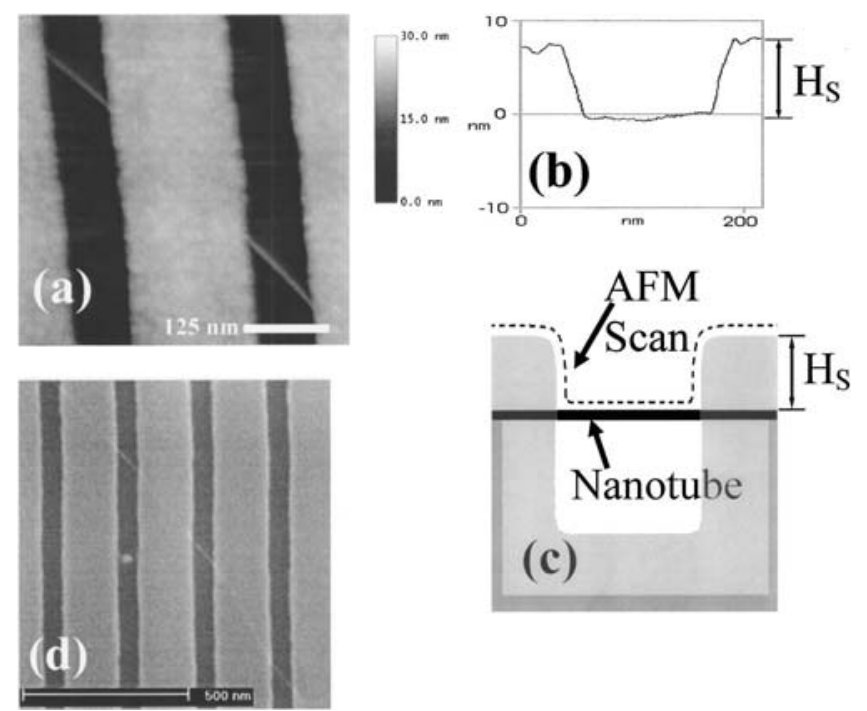

FIG. 5. NT suspended over trench after $\mathrm{SiO}_{2}$ deposition. (a) AFM height image. (b) Coaxial line scan of NT buried in $\mathrm{SiO}_{2}$ and suspended over trench from image in part (a) yielded a step height $H_{S}$ of $8.2 \mathrm{~nm}$. (c) Schematic diagram showing the path for the line scan in (b). (d) SEM image.

the trenches and CNTs for $55 \mathrm{~min}$ at $172{ }^{\circ} \mathrm{C}$. The sample was then imaged with AFM [Fig. 5(a)]. AFM height measurements showed a difference of $8.2 \mathrm{~nm}$ between the top of the NT and the top of the trenches [Figs. 5(b) and 5(c)]. This height difference shows that a film covered the NT where it was in contact with the substrate, but that very little or no film was deposited on the suspended region of the tube, confirming that we achieved selective $\mathrm{SiO}_{2}$ deposition. The SEM image in Fig. 5(d) shows both the covered and suspended segments of the NT under the deposited film.

The selectivity of the deposition is consistent with the expected surface chemistry. While the CNT, graphene surface should be chemically inert to $\mathrm{Si}\left(\mathrm{O}(\mathrm{O}) \mathrm{CCH}_{3}\right)_{4}$, surface silanols $(\equiv \mathrm{SiOH})$ of the patterned trench tops should readily react with $\mathrm{Si}\left(\mathrm{O}(\mathrm{O}) \mathrm{CCH}_{3}\right)_{4}$ to form acetic acid $\left(\mathrm{HOC}(\mathrm{O}) \mathrm{CH}_{3}\right)$ and $\equiv \mathrm{SiOSi}\left(\mathrm{O}(\mathrm{O}) \mathrm{CCH}_{3}\right)_{3}$. This is the start of the chemisorbed $\mathrm{SiO}_{2}$ layer, which continues to grow according to the previously mentioned reaction $\mathrm{Si}\left(\mathrm{O}(\mathrm{O}) \mathrm{CCH}_{3}\right)_{4}(\mathrm{~g}) \rightarrow \mathrm{SiO}_{2}(\mathrm{~s})+2\left(\mathrm{CH}_{3} \mathrm{CO}\right)_{2} \mathrm{O}(\mathrm{g}), \quad$ at $170^{\circ} \mathrm{C}$.

Silicon tetraacetate-based $\mathrm{SiO}_{2}$ CVD provides a self- aligned method to rigidly attach $\mathrm{CNTs}$ to $\mathrm{SiO}_{2}$ structures. Other oxide structures could also be compatible with this process, and should be explored. The self-aligned nature of the process will allow rigid NT attachment on threedimensional $\mathrm{SiO}_{2}$ structures such as AFM probe tips. This process is compatible with mass fabrication of CNT AFM probes and could aid in making them available to a wider range of researchers. This process may be particularly valuable for producing CNT AFM tips for fluid imaging, where rigid attachment to the tip is critical.

This work was supported by the National Science Foundation Center for Nanoscale Systems at Cornell University. The authors thank Scott Bunch and Paul L. McEuen for help in fabricating the trench substrate and growing the CNTs. We also thank Dean Barnett for help with the $\mathrm{SiO}_{2}$ thermal CVD heater design and Yit-Yen Lau for taking much of the XPS data.

${ }^{1}$ E. W. Wong, P. E. Sheehan, and C. M. Lieber, Science 277, 1971 (1997).

${ }^{2}$ P. Poncharal, Z. L. Wang, D. Ugarte, and W. A. de Heer, Science 283, 1513 (1999).

${ }^{3}$ J. H. Hafner, C.-L. Cheung, T. H. Oosterkamp, and C. M. Lieber, J. Phys. Chem. B 105, 743 (2001).

${ }^{4}$ H. Dai, J. H. Hafner, A. G. Rinzler, D. T. Colbert, and R. E. Smalley, Nature (London) 384, 147 (1996).

${ }^{5}$ S. Akita, H. Nishijima, Y. Nakayama, F. Tokumasu, and K. Takeyasu, J. Phys. D 32, 1044 (1999).

${ }^{6}$ R. Kerwin and D. Klein, U.S. Patent No. 3,475,234, 1969.

${ }^{7}$ R. C. Davis, C. C. Williams, and P. Neuzil, Appl. Phys. Lett. 66, 2309 (1995).

${ }^{8}$ T. Maruyama and J. Shionoya, Jpn. J. Appl. Phys. 28, L2253 (1989).

${ }^{9}$ J. F. Moulder, W. F. Stickle, P. E. Sobol, and K. D. Bomben, Handbook of $X$-ray Photoelectron Spectroscopy (Physical Electronics, Eden Prairie, MN, 1995).

${ }^{10}$ The relative areas of the $\mathrm{Si} 2 p$ peaks from bulk silicon and $\mathrm{SiO}_{2}$ were used to calculate the $\mathrm{SiO}_{2}$ film thickness using standard XPS theory [C. S. Fadley, R. J. Baird, W. Siekhaus, T. Novakov, and S. A. L. Berström, J. Electron Spectrosc. 4, 93 (1974)]. Literature values for the mean free paths of Si $2 p$ photoelectrons in silicon $(1.6 \mathrm{~nm})$ and silicon dioxide $(2.6$ $\mathrm{nm})$ were used in these calculations [M. F. Hochella and A. H. Carim, Surf. Sci. 197, L260 (1988); M. Suzuki, H. Ando, Y. Higashi, H. Takenaka, H. Shimada, N. Matsubayashi, M. Imamura, S. Kurosawa, S. Tanuma, and C. J. Powell, Surf. Interface Anal. 29, 330 (2000)]. Ellipsometry is known to yield thickness measurements up to $40 \%$ higher than XPS [M. F. Hochella and A. H. Carim, Surf. Sci. 197, L260 (1988)]. Here, our ellipsometry measurements were $\sim 25 \%$ higher than our XPS measured thicknesses, within the expected agreement of the methods. 